\title{
Study on the Constructive Strategies of Inclusive Financial System in Rural Areas of China: Taking Jilin Province as an Example
}

\author{
Jian Zhang \\ School of Economics and Management, Northeast Normal University, China
}

Received December 15, 2019; Revised January 28, 2020; Accepted February 3, 2020

Copyright $\bigcirc 2020$ by authors, all rights reserved. Authors agree that this article remains permanently open access under the terms of the Creative Commons Attribution License 4.0 International License

\begin{abstract}
Rural finance is the blood of rural economy. However, the rural financial problem has become a bottleneck restricting the development of rural economy, and the key to solve this problem is to develop the rural inclusive financial system. Taking Jilin Province as an example, through qualitative analysis and investigation analysis, this paper makes a comprehensive and systematic study on the construction strategies of inclusive financial system in rural areas of China. Different from the existing research, this paper includes two dimensions and two perspectives. Two dimensions include inclusive financial vertical system and inclusive financial horizontal system. Two perspectives include entity inclusive finance and digital inclusive finance. Specifically, this paper first discusses the general construction principles of the vertical and horizontal systems of inclusive finance in rural areas, and then puts forward and discusses the specific construction strategies of the inclusive financial vertical and inclusive financial horizontal systems in rural areas from the perspectives of entity inclusive finance and digital inclusive finance. The construction strategies of inclusive financial system proposed in this paper will provide an important reference for the development of inclusive finance in rural areas of Jilin Province, as well as for the development of inclusive finance in China or other rural areas in the world.
\end{abstract}

Keywords Rural Areas, Inclusive Financial System, Constructive Strategies, Jilin Province

\section{Introduction}

Rural finance is the blood of rural economy. However, for a long time, the loss of rural financial resources and the contradiction between financial supply and demand are very prominent. The main current situation is that a large amount of funds absorbed by financial institutions in rural areas have gone to cities with higher income and lower risk, while the funds urgently needed for rural economic development are not guaranteed. At present, the rural financial problem has become a bottleneck restricting the development of rural economy, and the key to solve this problem is to develop the rural inclusive financial system. On November 12, 2013, the Central Committee of the Communist Party of China put forward some decisions on several major issues concerning comprehensively deepening reform, and formally proposed "developing inclusive finance, encouraging financial innovation, and enriching financial market levels and products".

The concept of inclusive finance was put forward by the United Nations for the first time in 2005 to publicize the International Year of Microcredit. Specifically, inclusive finance takes the microcredit as the core, integrates the microcredit with sustainable development potential into the formal financial system, so as to include the low-income rural population into the scope of rural financial services, so that they can share the welfare improvement brought by the economic growth[1]. According to the blue book "Building Inclusive Financial Sectors for Development" of the United Nations in 2006, the goal of inclusive finance is that under a sound framework of policy, legal and regulatory, every developing country should have a complete set of financial institutions to jointly provide appropriate financial products and services for all levels of the population. Although the introduction of inclusive finance is relatively late, the practice of inclusive finance began as early as the 1970s. The initial form of inclusive finance is microcredit. The most representative inclusive financial institution is Grameen branch of Agricultural Bank of Bangladesh founded by Muhammad Yunus in Bangladesh. In the 1970s-1980s, microcredit developed rapidly in many developing countries in Asia, Africa and Latin America, and gradually became standardized and achieved sustainable development to a 
certain extent.

Jilin Province is a large agricultural province in China. The construction of inclusive financial system plays a very important role in the economic development of rural areas in Jilin Province. The state also attaches great importance to the development of inclusive finance in rural areas of Jilin Province. As early as 2006, China Banking Regulatory Commission selected rural areas of Jilin Province as the first pilot areas to carry out the construction of new rural financial institutions.

\section{Literature Review}

Corresponding to inclusive finance practice, the research before 2005 mainly focused on microcredit (Amin, Rai and Topa, 2003[2]; Hollis and Sweetman, 1998[3]), and the research after 2005 were more close to inclusive finance. Jones (2008) analyzed the role changes of British cooperative credit organizations in poverty eradication and inclusive finance, and the study found that cooperative credit organizations would be better if they were incorporated into the financial service industry[4]. Chakravarty and pal (2013) developed a method to measure the inclusive degree of inclusive finance, and further analyzed the inclusive degree of inclusive finance in India through panel analysis[5]. Vighneswara Swamy (2014) used panel data model to analyze the impact of inclusive finance on male dominated poor families and female dominated poor families[6]. Hema Gwalania and Shilpa Parkhib (2014) studied the various forms of inclusive finance used in India, and the challenges and solutions they faced[7]. Diniz, Birochi and Pozzebon (2012) [8], Shashank Bansal (2014) [9] focused on the important role of modern information and communication technology (ICT) in inclusive finance. Germana Corrado and Luisa Corrado (2017) analyzed the important role of inclusive finance in promoting sustainable economic growth[10]. Joy M Kiiru (2018) studied the moral hazard in the process of inclusive financial services[11].

Specific to the inclusive financial system in China's rural areas, the existing research mainly focuses on the following four aspects.

The first aspect focuses on the general idea of inclusive financial system. Mengliang Zhou and Mingxian Li (2011) analyzed and compared the two ideas of building inclusive financial system in China's rural areas, and on this basis, put forward the basic framework and countermeasures to coordinate the two ideas[12]. Wenpei Tan (2013) believed that in order to provide better financial products and services for the rural poor and low-income people, we must build a "three in one" rural inclusive financial system, in which the market, the government and the rural community are closely combined and can make up for each other's defects[13]. Jiujie Ma et al. (2013) analyzed the reasons for the underdevelopment of inclusive financial system in rural areas from the perspectives of supply and demand, as well as the overall and individual perspectives[14]. Shihong Zhang and Meiguang Zhao (2013) proposed the idea of building inclusive financial system in Jilin Province based on the current situation of financial supply and demand[15]. Siping Cai and $\mathrm{Li} \mathrm{Li} \mathrm{(2018)} \mathrm{studied} \mathrm{the} \mathrm{spatial} \mathrm{differences} \mathrm{and}$ agglomeration effects of inclusive financial development in rural areas[16].

The second aspect focuses on the institutions of inclusive financial system. Guangning Yan and Jingguang Ding (2007) took Yanchi County Microcredit Service Center in Ningxia as a typical case, and found that unofficial microfinance organizations play an important role in the inclusive financial system in rural areas[17]. Zhang Liang (2008) mainly discussed the important role and good prospects of rural banks and foreign banks in China's rural inclusive financial system[18]. Fei Meng (2011) discussed the financial exclusion of formal financial institutions to rural areas, and believed that cooperative financial organizations should be the core and basic strength of inclusive financial system in rural areas[19]. Jin Jia and Jian Xiao (2017) discussed institutional innovation in rural inclusive finance, with special emphasis on the important role of mutual fund cooperatives[20].

The third aspect focuses on the business operation of inclusive financial system. Zhuo Wang et al. (2008) believed that in order to become the mainstream of rural financial services, inclusive finance must reform the management of traditional rural finance and establish gender awareness of financial services[21]. Mingxian Li and Huimin Ye (2010) believed that inclusive financial institutions could reengineer inclusive financial loan technology through innovative risk assessment technology and risk dispersion mechanism[22]. Shuguang Wang and Dongbin Wang (2011) proposed a systematic policy framework for the incentive and constraint mechanism in the reform of inclusive financial system in rural areas [23]. Bo Wang et al. (2017) investigated the relationship between online lending and inclusive finance[24]. The research group of Changchun Finance College (2019) investigated the development of internet finance in rural areas of Jilin Province[25].

The fourth aspect focuses on the regulatory of inclusive financial system. Guofang Liu and Limei Qi (2009) thought that the regulatory system of small loan companies in China's rural inclusive financial system was not smooth[26]. Guohua Wu (2013) thought that in order to develop inclusive finance in China, laws and regulations need to be further improved[27]. Wenting Tang and Mingxian Li (2018) studied the government's behavior in the process of inclusive finance, as well as issues related to the protection of the rights and interests of rural financial consumers[28].

Generally speaking, the construction of inclusive financial system in rural areas of China is still lack of complete theoretical basis. There are only a few non-systematic studies on the construction of inclusive financial system in rural areas of Jilin Province. Different from the existing research, this paper includes two dimensions and two perspectives. 
Two dimensions include inclusive financial vertical system and inclusive financial horizontal system. Two perspectives include entity inclusive finance and digital inclusive finance.

\section{General Principles of Inclusive Financial System Construction in Rural Areas}

Next, this paper will discuss the general principles of inclusive financial system construction in rural areas of Jilin Province from the vertical and horizontal perspectives. The inclusive financial vertical system refers to the institutional network, software and hardware facilities, financial products and financial services that provide inclusive financial services for rural areas. The inclusive financial horizontal system refers to the spatial structure or regional structure of inclusive financial system in rural areas.

\subsection{General Principles of Inclusive Financial Vertical System Construction}

The author believes that the general principle of constructing the vertical system of inclusive finance in rural areas of Jilin Province should be efficiency priority.

The so-called efficiency priority emphasizes that with the shortest time and the lowest cost, as much as possible rural residents can get the best inclusive financial services, so as to construct a good vertical system of inclusive finance in rural areas as soon as possible. The principle of efficiency priority can be understood from two perspectives: the first is to use the shortest time and the least cost to achieve the same goal of inclusive financial vertical system construction in rural areas of Jilin Province; the second is to use the same time and cost to achieve the highest goal of inclusive financial vertical system construction in rural areas of Jilin Province。 From the concept of efficiency priority, we can also summarize two key points of efficiency priority, namely time efficiency and cost efficiency. Time efficiency is to measure efficiency from the dimension of time. Higher time efficiency means to achieve the expected goal in a shorter time. Cost efficiency is to measure efficiency from the dimension of capital. Higher cost efficiency means that less capital is used to achieve the expected goal.

Under the principle of efficiency priority, the author thinks that the overall arrangement of optimizing the vertical system of inclusive finance in Jilin Province should be: highlighting the leading position of the digital inclusive financial system, taking into account the structural optimization of the entity inclusive financial system. Entity inclusive financial system refers to the system structure of physical institutions, facilities and staff that provide inclusive financial services. Digital inclusive finance is an internet based inclusive finance, which is the result of the deep integration of internet technology and financial services. The specific forms include internet payment, internet lending, internet insurance, internet crowdfunding, internet financing and other internet based inclusive financial services. Compared with physical inclusive finance, digital inclusive finance can greatly reduce the cost and threshold of financial services, make inclusive financial services break through the restrictions of physical business outlets and business hours, and enable residents in rural areas to obtain convenient, efficient and low-cost financial services.

\subsection{General Principles of Inclusive Financial Horizontal System Construction}

The author believes that the general principle of constructing the horizontal system of inclusive finance in rural areas of Jilin Province should be balance priority.

The so-called balanced priority emphasizes that the inclusive financial system in rural areas with different economic development levels should go hand in hand, so as to achieve a more balanced spatial distribution of the inclusive financial system in rural areas as far as possible. The general principle of constructing the horizontal system of inclusive finance in rural areas of Jilin Province, which is balance priority, is exactly in line with the fundamental spirit of inclusive finance. The fundamental spirit of inclusive finance is to emphasize that people of different regions, different income levels and different education levels can enjoy the necessary financial services equally. The principle of balanced priority just explains this inclusive finance spirit in practice.

Under the principle of balance priority, the author thinks that the overall arrangement of optimizing the horizontal system of inclusive finance in Jilin Province should be: the rural areas with low economic development level give priority to the development of digital inclusive finance; the rural areas with middle economic development level give priority to the development of digital inclusive finance while giving consideration to the development of entity inclusive finance; the rural areas with high economic development level give priority to the development of entity inclusive finance while giving consideration to the development of digital inclusive finance. The reasons are as follows:

As two types of inclusive financial system, entity inclusive finance and digital inclusive finance need to invest a lot of funds in the early stage. For the rural areas with low economic development level, they may not be able to provide enough funds to promote the construction of both the entity inclusive financial system and the digital inclusive financial system. In this case, the rural areas with lower economic development level can only choose the digital inclusive finance with higher efficiency and lower cost for priority development, so as to reduce the gap between them and the rural areas with higher economic development level as soon as possible. For the same reason, the rural areas with the middle level of economic development should give priority to the development of digital inclusive finance, and the surplus funds can be used for the development of entity 
inclusive finance. Only in this way can we narrow the development gap between them and the rural areas with higher economic development level as soon as possible.

\section{Construction Strategies of the Vertical System of Inclusive Finance in Rural Areas}

\subsection{Construction Strategies of the Vertical System of Entity Inclusive Finance}

\subsubsection{Construction Strategies of Supply System}

First, we should make corresponding laws and regulations to limit the "de farming" trend of large-scale agricultural related financial institutions. The author finds that the supply capacity of inclusive finance of large-scale agricultural financial institutions in rural areas of Jilin Province tends to weaken. Specifically, the number of business outlets of Agricultural Bank of China, Postal Savings Bank of China and Agricultural Development Bank of China in Jilin Province has a decreasing trend (refer with: Fig. 1); the number of employees of Agricultural Bank of China and Agricultural Development Bank of China in Jilin Province also has a decreasing trend (refer with: Fig. 2). The weakening of the supply capacity of inclusive finance of large-scale agricultural financial institutions makes it difficult to construct the vertical supply system of entity inclusive finance in Jilin Province. In this case, the author believes that we should make corresponding laws and regulations to limit the "de farming" trend of large-scale agricultural related financial institutions.

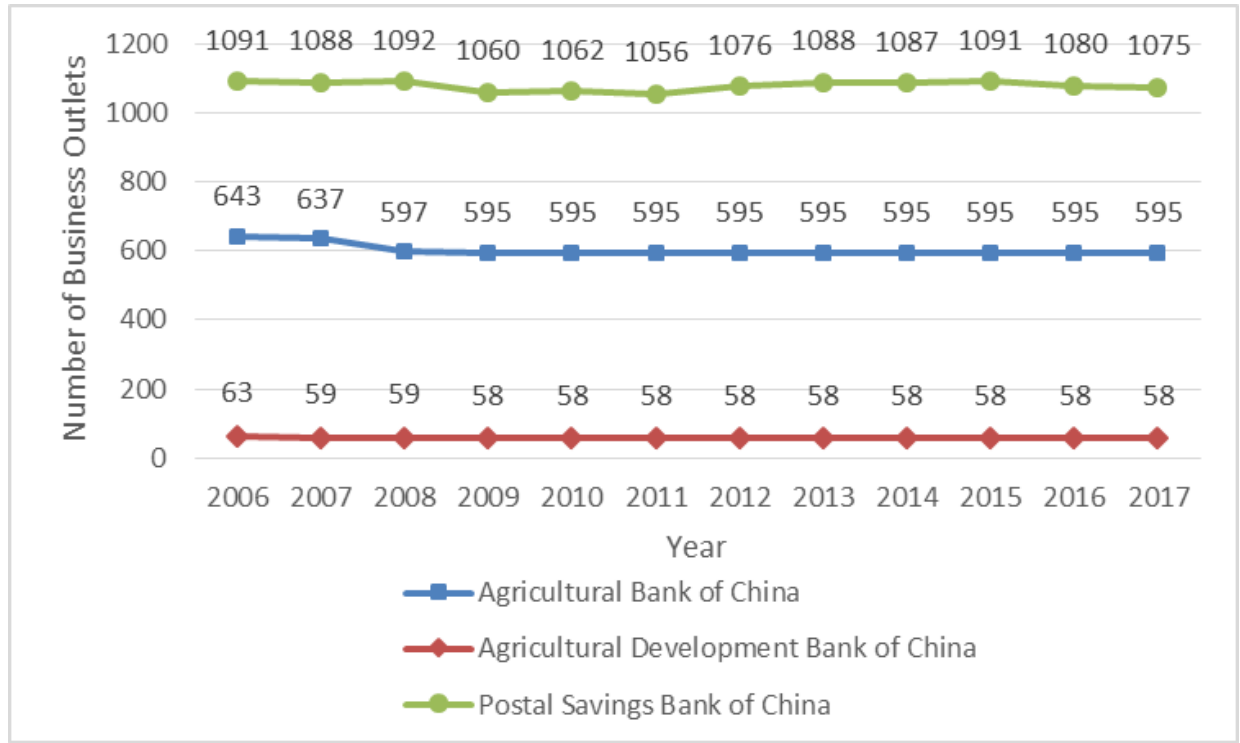

Figure 1. The number of business outlets of large-scale agricultural related financial institutions in Jilin Province (Data source: Wind)

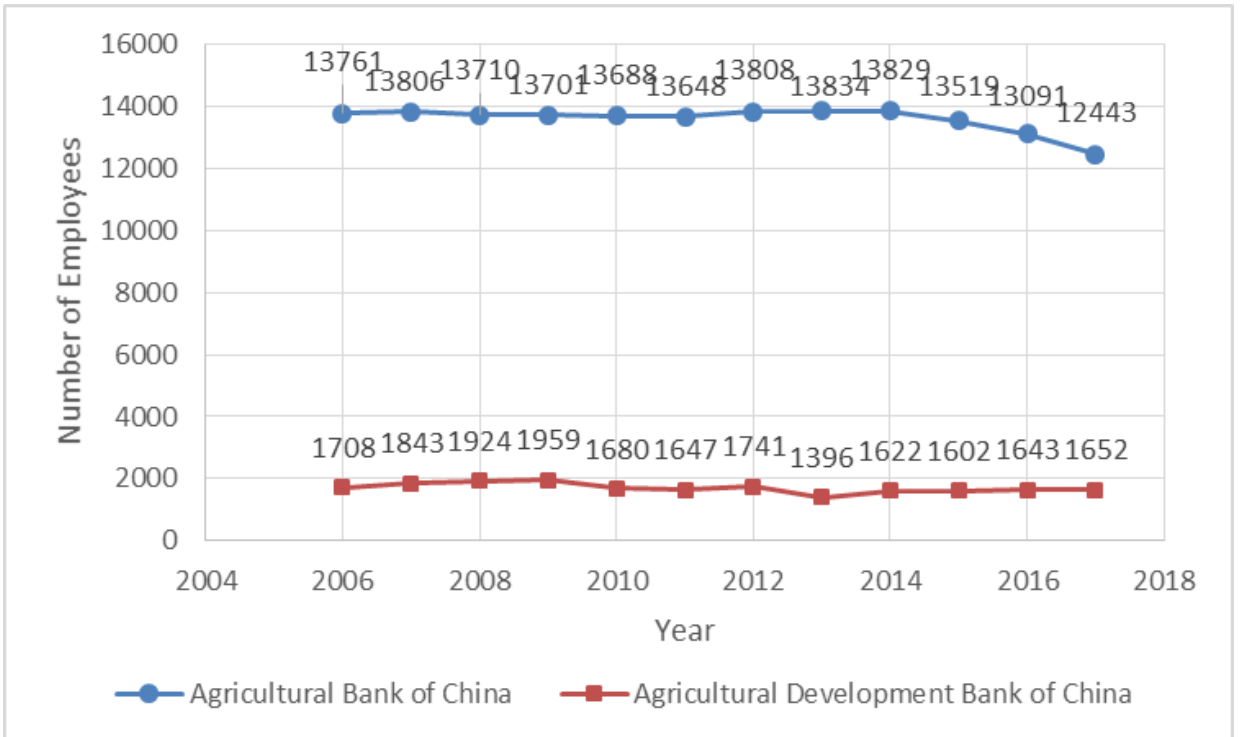

Figure 2. The number of employees of large-scale agricultural related financial institutions in Jilin Province (Data source: Wind) 


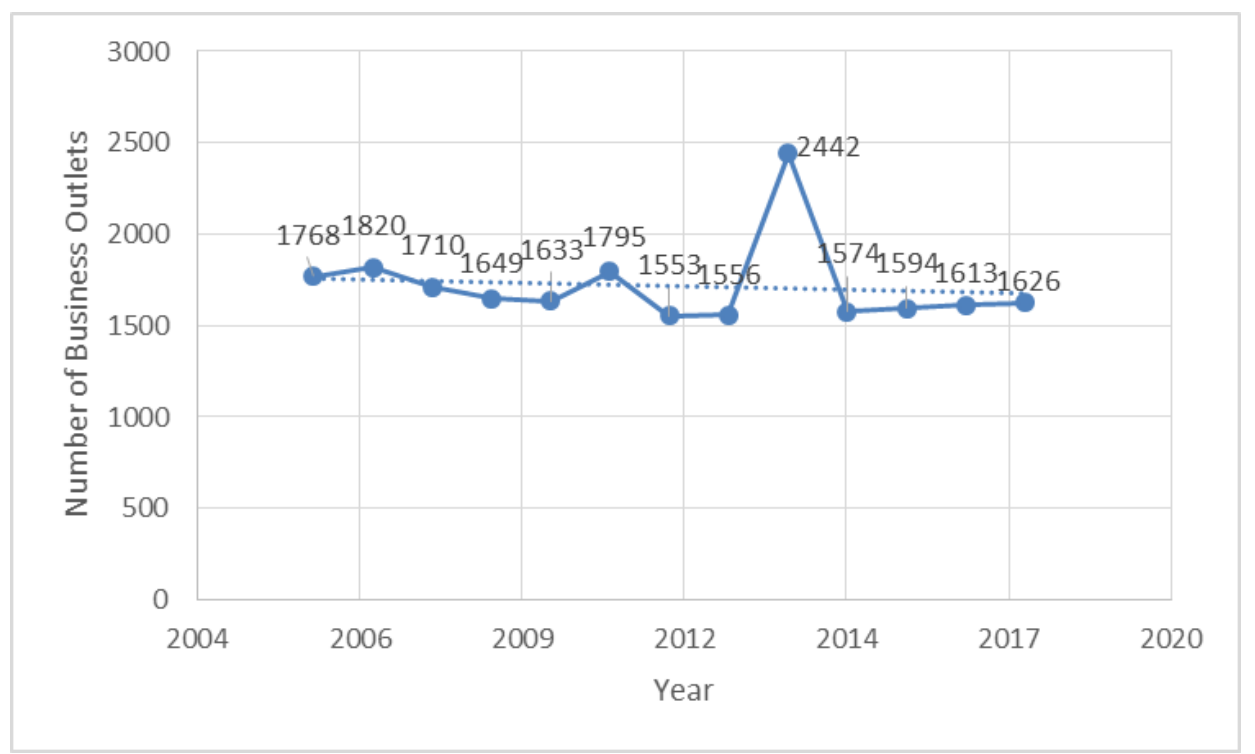

Figure 3. The number of business outlets of small rural financial institutions in Jilin Province (Data source: Wind)

Second, we should improve the policy advantages of small rural financial institutions. The author finds that small rural financial institutions such as Jilin Rural Commercial Bank, rural cooperative banks and rural credit cooperatives also reduce the ability of inclusive financial supply for rural residents in Jilin Province. Specifically, the number of small rural financial institutions in Jilin Province has a decreasing trend. The number of small rural financial institutions in 2005 was 1768, compared with 1626 in 2017 (refer with: Fig. 3 ). In this case, the author thinks that we can improve the inclusive financial supply capacity of small rural financial institutions by improving the policy advantages of small rural financial institutions. Specifically, it can include the following measures: (1) it is suggested that the government deposit the relevant special funds for supporting agriculture in small rural financial institutions, which can realize the direct support for small rural financial institutions on one hand, and on the other hand, it can find a new loan mortgage for small rural financial institutions when granting agricultural related loans; (2) it is suggested that the government should appropriately relax the business scope of small rural financial institutions, allow small rural financial institutions to invest part of the surplus funds in other fields after fully satisfying the agricultural loans, so as to increase the income of small rural financial institutions and indirectly reduce the cost of agricultural loans; (3) it is suggested to further reduce the deposit reserve ratio of small-scale rural financial institutions, so that small-scale rural financial institutions can have more funds to invest in the field of "agriculture, rural areas and farmers"; (4) it is suggested to further improve the loan-to-deposit ratio of small rural financial institutions, so that small rural financial institutions can have more funds to invest in the field of "agriculture, rural areas and farmers".

Third, we should strengthen the guidance and support for the new rural financial institutions. The author finds that the supply capacity of inclusive finance of new rural financial institutions, such as rural banks, rural small loan companies and mutual fund cooperatives, is insufficient. Specifically, in recent years, many new rural financial institutions only stay in the registration stage and do not open business outlets that actually provide inclusive financial services. Compared with large-scale agricultural financial institutions and small-scale rural financial institutions, the new rural financial institutions have strong flexibility and regional adaptability, so the author believes that the inclusive financial supply capacity of the new rural financial institutions in rural areas of Jilin Province should be greatly improved. Specifically, the author believes that efforts should be made from two aspects: (1) the government should formulate corresponding laws and regulations to guide and restrict the investment direction of rural banks, and ensure as much capital as possible to be invested in the field of "agriculture, rural areas and farmers"; (2) the government should give necessary policy and financial support to the rural banks so that they can develop healthily.

Fourth, we should strengthen the construction of rural financial infrastructure. It is suggested to carry out the "village to village" project of financial services, so that rural residents can enjoy the most basic inclusive financial services without leaving the village, such as deposit and withdrawal, loan and remittance, etc. Specifically, to strengthen the construction of rural financial infrastructure includes the establishment of business outlets of financial institutions, micro banking offices, ATM machines and financial service agency points, etc. The specific participants in strengthening the construction of rural financial infrastructure include large agricultural financial institutions represented by Agricultural Bank of China, small rural financial institutions represented by rural commercial banks and new rural financial institutions represented by community banks. In this process, the government should focus on the overall planning and guidance. 


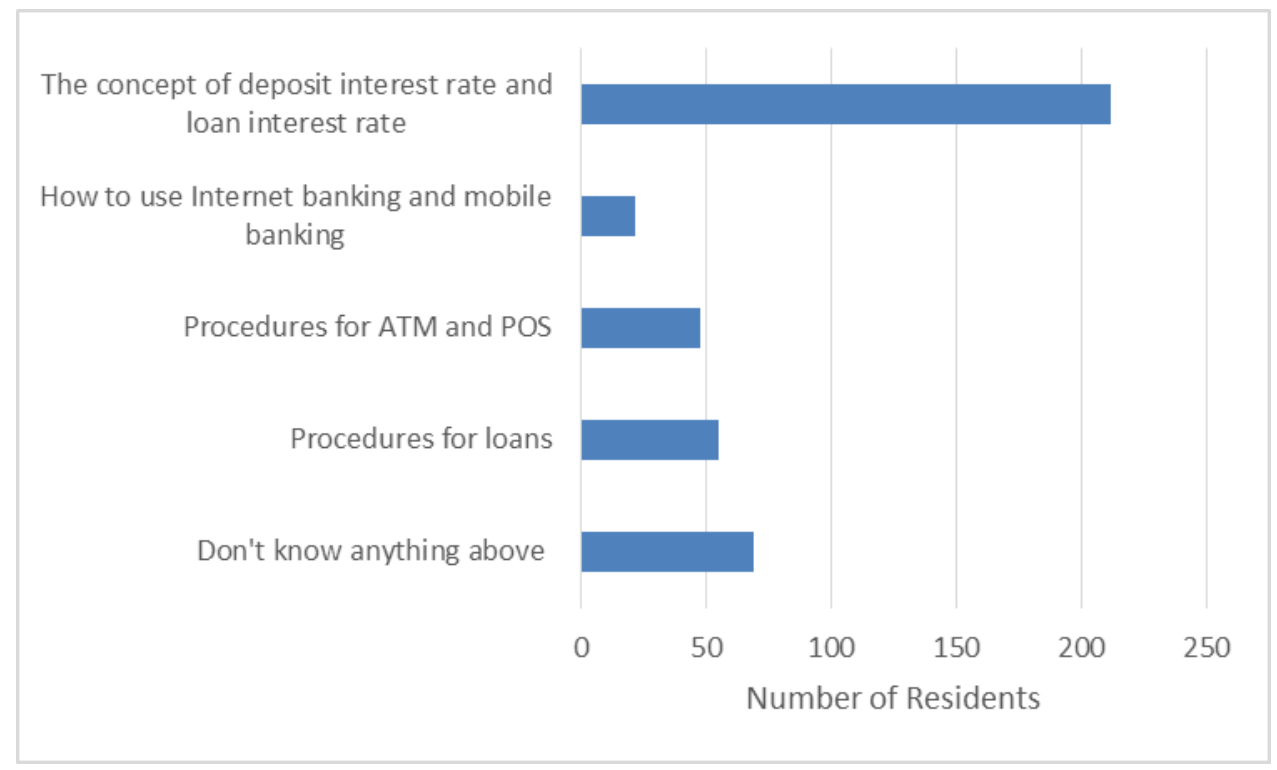

Figure 4. The number of rural residents with basic financial knowledge (Data source: The author investigated 300 rural residents in Jilin Province)

\subsubsection{Construction Strategies of Demand System}

First, we should carry out precise inclusive financial training in rural areas of Jilin Province. The purpose of carrying out precise inclusive financial training in rural areas of Jilin Province is to improve the financial knowledge and financial literacy of residents in rural areas of Jilin Province, as well as the ability to use financial facilities and financial services. The author found that in rural areas of Jilin Province, a considerable number of residents lack the necessary financial knowledge and financial literacy (refer with: Fig. 4), which limits their demand for modern financial services. In this case, carrying out precise inclusive financial training in rural areas of Jilin Province will be an effective means to change this situation. Accurate inclusive financial training includes two aspects: (1) training of basic financial knowledge, through which rural residents can learn more about financial knowledge; (2) training of use methods of financial facilities and financial services, through which rural residents can use financial facilities and financial services more easily. Specific training measures include: first, set specific responsible areas for different types and levels of financial institutions by the government, then further set specific responsible rural households for relevant staff by different types and levels of financial institutions, and finally, the relevant staff conduct accurate training for the responsible rural households.

Second, it is suggested to provide precise guidance for the financing planning of rural residents. The purpose of giving precise guidance to the financing planning of rural residents is to help them form reasonable financing demands and find reasonable financing channels. The author finds that the financing needs and channels of rural residents in Jilin Province are not always reasonable. Specifically, a considerable number of rural residents' financing needs are mainly limited to their living purposes rather than production purposes; a considerable number of residents have applied for loans from formal financial institutions; nearly half of the residents will choose private financing with higher interest rates. In this case, I think it is necessary to guide the financing needs and financing channels of rural residents in Jilin Province accurately.

Third, it is suggested to accurately tap the loan capacity of rural residents in Jilin Province. The author finds that rural residents in Jilin Province are facing the problem of loan difficulty, which is not only caused by the supply of financial institutions, but also by the problems of rural residents themselves, such as low credit, insufficient collateral, no guarantee, unfamiliar with the process and procedures of loan, and so on. The author believes that it is necessary to improve the loan ability of rural residents in Jilin Province by innovating mortgage and guarantee forms. Specific measures can include: (1) it is suggested to continue to make loans with grain direct subsidy as mortgage; (2) it is suggested to provide loans secured by land management rights; (3) it is suggested to strengthen government subsidies to solve the problem of high financing cost for rural residents.

\subsection{Construction Strategies of the Vertical System of Digital Inclusive Finance}

\subsubsection{Construction Strategies of Supply System}

First, it is suggested to promote broadband access in rural areas of Jilin Province. The author finds that although all administrative villages in rural areas of Jilin Province have access to fixed broadband, but many rural families have not achieved fixed broadband access, which limits the ability of rural residents in Jilin Province to use digital inclusive financial services through terminal equipment such as computers. In this case, the author thinks it is necessary to further expand the coverage of fixed broadband in rural areas of Jilin Province, strive for broadband access to groups and households, and at the same time, improve the network speed 
of fixed broadband and reduce the rate of fixed broadband. Specific measures can include: (1) the government and communication companies cooperate to develop a low-cost broadband network suitable for rural residents; (2) the government provides a certain degree of subsidies for broadband access of rural residents in Jilin Province.

Second, it is suggested to expand the penetration rate of mobile broadband in rural areas of Jilin Province. The author found that although the penetration rate of mobile phone is very high, the penetration rate of $4 \mathrm{G}$ and $5 \mathrm{G}$ still needs to be further improved. Generally speaking, compared with fixed broadband, mobile broadband should play a greater role in the development of digital inclusive finance in rural areas of Jilin Province, because the access cost of mobile broadband is lower and the use is more convenient. In this case, I think it is necessary to expand the coverage of mobile broadband in rural areas of Jilin Province, speed up and reduce fees. Specific measures include: the government and mobile communication companies cooperate to speed up the construction of mobile broadband base stations in rural areas; the government and mobile communication companies cooperate to offer low-cost mobile network packages suitable for rural areas of Jilin Province.

\subsubsection{Construction Strategies of Demand System}

The author believes that the main construction strategy of the vertical demand system of digital inclusive finance in rural areas of Jilin Province should be to carry out accurate digital inclusive financial training in rural areas of Jilin Province. The author finds that: in rural areas of Jilin Province, there are still many people who have not used digital inclusive financial services such as online banking; rural residents mainly rely on entity inclusive financial services such as bank counter when handling general financial services such as deposit, withdrawal and remittance; there are also many people who are not willing to use digital inclusive financial services such as mobile banking and online banking. In this case, I think it is necessary to carry out precise digital inclusive financial training in rural areas of Jilin Province, to guide rural residents to try the financial services provided by digital inclusive finance, so as to gradually improve the demand willingness of rural residents in Jilin Province for digital inclusive financial. As almost all college students can skillfully use digital financial tools, the training of digital inclusive finance can also be carried out by college students. Specific training measures include: first, set specific responsible areas for local universities and colleges by the government, then further set specific responsible rural households for college students by local universities and colleges, and finally, the college students conduct accurate training for the responsible rural households.

\section{Construction Strategies of the Horizontal System of Inclusive Finance in Rural Areas}

\subsection{Construction Strategies of the Horizontal System of Entity Inclusive Finance}

First, it is suggested that more inclusive financial institutions, financial facilities and financial services should be set up in rural areas with low economic development level. The author finds that the spatial distribution of financial institutions and financial facilities in rural areas of Jilin Province is not balanced (refer with: Fig. 5), the rural areas with low level of economic development lack sufficient financial institutions outlets, financial facilities and financial services. Based on the theory of spatial economics, due to the existence of cyclic cumulative causality, the lack of sufficient financial institutions, financial facilities and financial services in rural areas with low level of economic development in Jilin Province will further weaken the level of economic development, and in turn may lose more financial institutions, financial facilities and financial services, thus forming a vicious cycle ring. In this case, to break this vicious circle, we need to arrange more financial institutions, financial facilities and financial services in rural areas with low economic development level under the coordination and promotion of the government. 


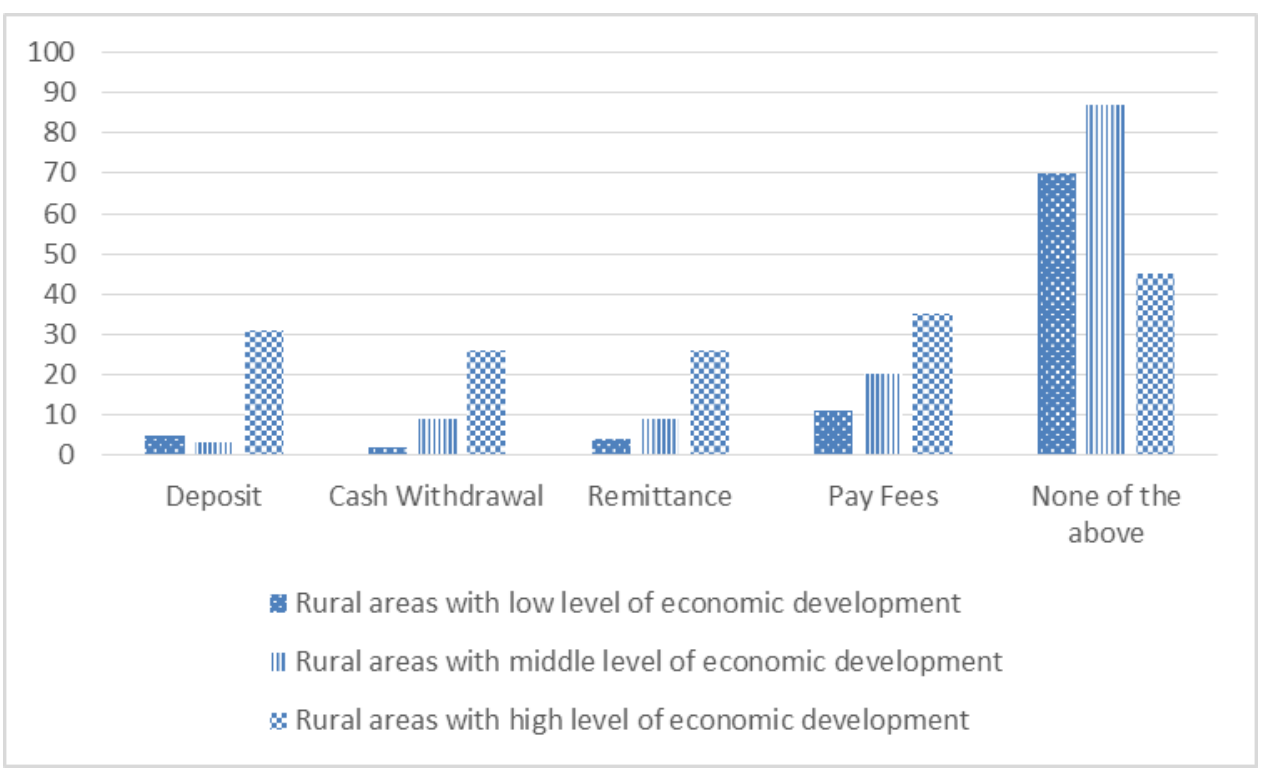

Figure 5. The number of rural residents who can get financial services in the village (Data source: The author investigated 300 rural residents in Jilin Province)

Second, it is suggested to carry out more targeted financial training in rural areas with low economic development level. The author finds that the ability of rural residents to accept financial services in Jilin Province is not balanced: the proportion of households without bank accounts is relatively smaller in the higher level of economic development; the number of visits to bank outlets by rural households with higher level of economic development is relatively higher; the rural residents with higher economic development level have more open ideas and pay more attention to education, so the education level and financial literacy of the investigated family members are relatively higher; the family income of the rural residents with lower economic development level is also lower. This spatial imbalance greatly limits the ability of rural residents with low economic development level to accept inclusive financial services. In this case, I think it is necessary to carry out more targeted financial training in rural areas with low economic development level.

Third, it is suggested that the province's inclusive financial resources should be allocated as a whole. The author finds that there is a problem of spatial dislocation between the financing demand and the financing supply in rural areas of Jilin Province: from the perspective of financing demand, the residents in rural areas with the middle and lower level of economic development apply for loans from financial institutions relatively more, while the residents in rural areas with the higher level of economic development apply for loans from financial institutions relatively less; from the perspective of financing supply, rural residents with higher economic development level get more loans from formal financial institutions, more channels to obtain loans, and more ways to obtain loans, while rural residents with lower economic development level get less loans from formal financial institutions, less channels to obtain loans, and less ways to obtain loans, and even have to use high interest rate private financing. This spatial dislocation between the financing demand and financing supply leads to the limited inclusive financial resources cannot be more effectively allocated. In this case, the author thinks that this problem can be solved by the government's overall allocation of inclusive financial resources in the province.

\subsection{Construction Strategies of the Horizontal System of Digital Inclusive Finance}

The author believes that the main construction strategy of the horizontal system of digital inclusive finance in rural areas of Jilin Province should be to carry out more accurate digital inclusive finance training in rural areas with lower economic development level. The author finds that there is a regional imbalance in the willingness and degree of use of digital inclusive finance in rural areas of Jilin Province: in rural areas with a high level of economic development, the willingness and degree of use of digital inclusive financial services or products by rural residents are significantly higher than those in other areas. For rural residents with lower level of economic development, the lower willingness to use digital inclusive financial services or products further limits their access to digital inclusive financial services, and also limits the development of horizontal digital inclusive financial system in rural areas of Jilin Province. In this case, the author believes that we should carry out more accurate digital inclusive financial training in rural areas with lower economic development level in Jilin Province, enhance the willingness of rural residents with lower economic development level to use digital inclusive financial services, and rapidly promote the development of digital inclusive financial in rural areas with lower economic development level through demand driven supply, then realize the balanced development of digital inclusive finance in rural 
areas of the province.

\section{Conclusions}

In conclusion, this paper taking Jilin Province as an example makes a comprehensive and systematic study on the construction strategies of inclusive financial system in rural areas of China. Different from the existing research, this paper includes two dimensions and two perspectives. Two dimensions include inclusive financial vertical system and inclusive financial horizontal system. Two perspectives include entity inclusive finance and digital inclusive finance. Specifically, this paper first discusses the general construction principles of the vertical and horizontal systems of inclusive finance in rural areas, and then puts forward and discusses the specific construction strategies of the inclusive financial vertical and inclusive financial horizontal systems in rural areas from the perspectives of entity inclusive finance and digital inclusive finance.

\section{Acknowledgements}

This research was financially supported by the Science and Technology Development Plan of Jilin Province (Grant NO. 20150418011FG).

\section{REFERENCES}

[1] Jinpu Jiao. Microcredit in China [J]. China Financialyst, 2007(4):60-64.

[2] Amin, Rai and Topa. Does Microcredit Reach the Poor and Vulnerable? Evidence From Northern Bangladesh[J]. Journal of Development Economics, 2003, 70(1):59-82.

[3] Hollis and Sweetman. Microcredit: What Can We Learn From the Past?[J]. World Development, 1998, 26(10): 1875-1891.

[4] Jones. From Tackling Poverty to Achieving Financial Inclusion-The Changing Role of British Credit Unions in Low Income Communities [J]. The Journal of Socio-Economics, 2008, 37(6): 2141-2154.

[5] Chakravartya, Pal. Financial Inclusion in India: An Axiomatic Approach[J]. Journal of Policy Modeling, 2013, 35(5): 813-837.

[6] Vighneswara Swamy. Financial Inclusion, Gender Dimension, and Economic Impact on Poor Households[J]. World Development, 2014(56): 1-15.

[7] Hema Gwalania, Shilpa Parkhi. Financial Inclusion - Building a Success Model in the Indian Context[J]. Procedia - Social and Behavioral Sciences, 2014(133):372-378.

[8] Diniz, Birochi, Pozzebon. Triggers and Barriers to Financial Inclusion: The use of ICT-based Branchless Banking in an Amazon County[J]. Electronic Commerce Research and Applications, 2012, 11(5): 484-494.

[9] Shashank Bansal. Perspective of Technology in Achieving
Financial Inclusion in Rural India[J]. Procedia Economics and Finance, 2014(11):472-480.

[10] Germana Corrado, Luisa Corrado. Inclusive Finance for Inclusive Growth and Development [J]. Current Opinion in Environmental Sustainability, 2017(24):19-23.

[11] Kiiru Joy M. Institutional Moral Hazard and Inclusive Finance: When Good is Not so Good[J]. OIDA International Journal of Sustainable Development, 2018, 11(03):23-34.

[12] Mengliang Zhou, Mingxian Li. China's Rural Finance "Double Line" Reform Ideas: Comparison and Coordination [J]. Comparative Economic \& Social Systems, 2011(4): 76-84.

[13] Wen-pei Tan. On Constructing the Rural Inclusively Financial System from the Perspective of "Trinity"[J]. Journal of Hunan University of Science \& Technology(Social Science Edition), 2013, 16(6):85-88.

[14] Jiujie Ma, Benjian Wu, Xiangyang Zhou. The Performance, Causes of Rural Financial Underdevelopment and the Construction of Inclusive Financial System [J]. Theoretical Investigation, 2013(2): 74-78.

[15] Shihong Zhang, Meiguang Zhao. Reflections on the Construction of Inclusive Financial System: Take Jilin Province as Example [J]. Journal of Jilin Financial Research, 2013(9): 57-60.

[16] Siping Cai, Li Li. The Research on the Spatial Difference and Agglomeration Effects of the Rural Inclusive Finance in China $[\mathrm{J}]$. The Theory and Practice of Finance and Economics, 2018, 39(03): 27-33.

[17] Guangning Yan, Jingguang Ding. Microcredit: Innovation of Rural Inclusive Financial System [J]. China Finance, 2007(18):69-71.

[18] Liang Zhang. Current Situation and Development Prospect of Rural Financial Market in China [J]. Academics, 2008(1):101-105.

[19] Fei Meng. Financial Exclusion: Problems and Governing Path [J]. Shanghai Journal of Economics, 2011(6): 80-89.

[20] Jin Jia, Jian Xiao. The Innovative Development of Rural Inclusive Financial System in the Context of Taking Targeted Measures for Poverty Alleviation [J]. Theoretical Investigation, 2017 (01):70-75.

[21] Zhuo Wang, Xiaoyu Li, Di Wu. Gender Analysis of Rural Folk Finance in China [J]. Social Science Research, 2008(2): 124-132.

[22] Mingxian Li, Huimin Ye. Research on the Technology Reengineering of Rural Inclusive Financial Loans in China [J]. Seeker, 2010(9):8-10.

[23] Shuguang Wang and Dongbin Wang. Double Financial Dualism, Credit Demand of Farmers and Rural Financial Reform: Based on Field Investigation of 14 Counties in 11 Provinces [J]. Finance \& Trade Economics, 2011(5): 38-44.

[24] Bo Wang, Xiao-mei Zhang, Lu Lu. Is P2P Lending an Effective Way to Realize Inclusive Finance: Evidence from RENRENDAI.COM [J]. China Industrial Economics, 2017(2):98-116.

[25] Research Group of Changchun Finance College. Investigation Report on the Development of Internet Finance in Rural 
104 Study on the Constructive Strategies of Inclusive Financial System in Rural Areas of China: Taking Jilin Province as an Example

Areas of Jilin Province [J]. Journal of Changchun Finance College, 2019, 144(01):56-71.

[26] Guofang Liu, Limei Qi. Research on the Development of Rural Microcredit Companies [J]. Economic Review Journal, 2009(12): 94-97.

[27] Guohua Wu. Improving China's Rural Inclusive Finance System [J]. Comparative Economic \& Social Systems, 2013(4):32-45.

[28] Wenting Tang, Mingxian Li. Government Behavior of Financial Inclusion and Protection of Rural Financial Consumers' Rights and Interests [J]. Finance \& Economics, 2018(11): 3-14. 